\title{
Procedimentos analíticos em perícia ambiental e eletroforese
}

O método mais exato para certa determinação pode ser muito demorado ou envolver o uso de reagentes caros. Por tal motivo, o apropriado é avaliar que exatidão se faz necessária. Em muitos casos, é possível escolher um método que, embora menos exato, proporcione, num tempo razoável, resultados satisfatórios.

Palavras-chave: Eletroforese; Perícia Ambiental; Procedimentos Analíticos.

\section{Analytical procedures in environmental expertise and electrophoresis}

The most accurate method for certain determination can be very time-consuming or involve the use of expensive reagents. For this reason, it is appropriate to assess what accuracy is necessary. In many cases, it is possible to choose a method that, although less accurate, provides satisfactory results in a reasonable time.

Keywords: Electrophoresis; Environmental Expertise; Analytical Procedures.

Topic: Biotecnologia

Reviewed anonymously in the process of blind peer.
Received: $12 / 08 / 2020$

Approved: 15/12/2020
Cleber Vinicius Vitorio da Silva (iD)

Universidade Federal Rural do Rio de Janeiro, Brasil

http://lattes.cnpq.br/4275890458575782

http://orcid.org/0000-0001-8337-9615

clebervitorio88@gmail.com

\section{Elenice Rachid da Silva Lenz (id}

Universidade do Estado do Rio de Janeiro, Brasil

http://lattes.cnpq.br/4557023865361858

http://orcid.org/0000-0002-1440-4271

erachid@pet.coppe.ufri.br

\section{Gustavo Aveiro Lins}

Universidade Federal Rural do Rio de Janeiro, Brasil

http://lattes.cnpq.br/5173989372426437

http://orcid.org/0000-0002-0244-6925

gustavoaveiro@gmail.com
Josimar Ribeiro de Almeida

Universidade do Estado do Rio de Janeiro, Brasil

http://lattes.cnpq.br/3215586187698472

http://orcid.org/0000-0001-5993-0665

almeida@poli.ufri.br

Lais Alencar de Aguiar (iD

Comissão Nacional de Energia Nuclear, Brasil

http://lattes.cnpq.br/5785500333245448

http://orcid.org/0000-0002-1551-4085

aguiar.lais@gmail.com d

DOI: 10.6008/CBPC2674-6441.2020.002.0001
Referencing this:

SILVA, C. V. V.; LENZ, E. R. S.; LINS, G. A.; ALMEIDA, J. R.; AGUIAR, L. A.. Procedimentos analíticos em perícia ambiental e eletroforese. Naturae, v.2, n.2, p.1-5, 2020. DOI: http://doi.org/10.6008/CBPC26746441.2020 .002 .0001 


\section{INTRODUÇÃO}

Dispondo-se de uma amostra apropriada, é necessário dedicar atenção à técnica, ou às técnicas, mais convenientes de serem empregadas para as determinações requeridas. Uma das decisões principais, a ser tomada pelo analista, é a da escolha do procedimento mais eficiente de uma dada análise; para chegar à decisão correta, o analista deve ter familiaridade com os detalhes práticos das diversas técnicas e com os princípios teóricos sobre os quais se baseiam: deve também ter o conhecimento das condições em que cada método é confiável e a consciência das interferências possíveis que podem ocorrer, e ser capaz de imaginar caminhos para evitar estes problemas. 0 analista também terá atenção às questões relativas à exatidão e à precisão esperável dos métodos dados e, além disso, não deve desprezar fatores como tempo e custo.

\section{RELATO}

Apesar das vantagens diversificadas dos métodos instrumentais, a sua generalizada adoção não tornou obsoletos os métodos clássicos; três fatores principais influenciam a situação: A aparelhagem necessária para os procedimentos clássicos é barata e encontra se com facilidade em todos os laboratórios; muitos instrumentos, no entanto são caros e a sua adoção só se justifica quando são muitas as amostras a analisar, ou quando se trata da determinação de substâncias em quantidades diminutas (análise de traços, subtrações ou ultratraços). Nos métodos instrumentais é necessário efetuar uma operação de calibração, em que se usa amostra do material com a composição conhecida como a substância de referência. Enquanto um método instrumental é o ideal para a execução de um grande número de determinações de rotina, no caso de uma análise episódica, fora da rotina, é muitas vezes mais simples usar um método clássico do que ter o trabalho de preparar os padrões indispensáveis e calibrar o instrumento.

\section{DISCUSSÃO}

Importante destacar que as pesquisas orientadas pelo método dialético revelam a historicidade do fenômeno e suas relações, em nível mais amplo, situam o problema dentro de um contexto complexo, ao mesmo tempo, estabelece e aponta as contradições possíveis dentre os fenômenos investigados. A investigação qualitativa é alicerçada na inseparabilidade dos fenômenos e seu contexto, pois, as opiniões, percepções e significados serão compreendidos com maior profundidade a partir da contextualização. A validade seria referente à semelhança entre o conceito e suas medidas, ao grau em que uma medida representa precisamente o que se espera. A garantia da validade começaria com a compreensão direta do que deve ser medido, sendo, portanto, uma questão de formulação da pesquisa. O método proposto foi dividido em três fases, as quais foram subdivididas em etapas para a realização do levantamento bibliográfico. Na primeira fase da pesquisa (perguntas de pesquisa) verifica-se as principais decisões e definições acerca da pesquisa. As perguntas de pesquisa, ficam em destaque e servem como impulsos para o início da revisão. Define-se o tema para realizar o levantamento bibliográfico e o período disponível. Outras decisões são tomadas simultaneamente. Tais como a definição das palavras-chave, para atuarem como 
identificadores. Paralelamente, resumem os principais assuntos sobre o tema a se pesquisar; assim como as combinações das palavras-chave. Essas, por sua vez, podem ser feitas por meio da utilização dos operadores booleanos e em diferentes bases de dados tais como Portal de Periódicos CAPES, Base de dados SCIELO, Publish or Perish, EBSCO, entre outras. No presente caso, as bases de dados foram Web of Science (ou ISI), Plataforma SUSTENERE, Scielo e Scopus. Essas bases possuem fácil acesso, permitindo, por meio de suas ferramentas, uma pesquisa criteriosa seja realizada, abrangendo uma vasta quantidade de periódicos. A segunda fase (Seleção dos artigos) inicia o levantamento e a seleção dos artigos, utilizando-se dos critérios de exclusão. Utiliza-se das palavras-chave de exclusão para realizar classificação mais criteriosa dos artigos. Delimitando também o período. Na etapa seguinte ocorre o primeiro filtro dos artigos, faz-se uma seleção a partir dos títulos, identificando os não alinhados. Na próxima etapa se faz a leitura dos resumos para excluir os impertinentes ao tema pesquisado. A etapa seguinte contém uma análise subjetiva do pesquisador para identificar, nos artigos alinhados ao tema, aqueles que possuem maior relevância acadêmica. Uma análise bibliométrica indica a relevância do autor/artigo para a composição do referencial bibliográfico. A Fase 3 corresponde a Classificação dos artigos selecionados. Procede-se a organização das amostras de artigos selecionados. O objetivo é ordenar, um padrão que vai variar de acordo com a necessidade do pesquisador e a prioriza como foco para desenvolvimento temático. Evidencia-se a importância da análise minuciosa dos artigos que compõem a amostra. Em pesquisas qualitativas, a concepção de validade assume formas distintas, pois a discussão sobre escalas de medição não se aplica a métodos qualitativos, sendo necessária a compreensão da validade em outra perspectiva. Um atributo que se relaciona com a objetividade, com a possibilidade de repetição do experimento, com o fato de a pesquisa estar aberta à verificação por outras pessoas e com a capacidade de generalização. A validade pode ser vista genericamente como a correspondência entre a pesquisa e a realidade (ALMEIDA et al., 2019). Ela se refere à verificação dos resultados como verdadeiros e confiáveis. Ela estaria relacionada ao fato de os resultados refletirem com precisão a situação analisada e serem confiáveis, no sentido de que não haveria razões para deles duvidar; ou seja, a pesquisa é válida se as evidências fornecem o apoio necessário às suas conclusões (ALMEIDA, 2019). A intenção não é generalizar, mas sim descrever, analisar, buscar compreender.

\section{CONSIDERAÇÕES FINAIS}

Eletroforese constitui o fenômeno da migração de partículas eletricamente carregadas quando submetidas a um campo elétrico. Se a carga da superfície da partícula iônica considerada for positiva, sua migração será no sentido de alcançar o catodo; se for negativa a partícula migrará para o anodo. $\mathrm{O}$ fator mais importante pelo qual a eletroforese se distingue de outras técnicas de separação de componentes de uma mistura repousa no fato de todas as partículas de mesma espécie possuírem a mesma carga e se repelirem mutuamente, evitando assim conglomerações, formação de complexos e inter-relações. Cada partícula migra independentemente das outras, na forma mais estável e quimicamente menos reativa, conservando deste modo sua estrutura e propriedades. A técnica eletroforética é aplicável a todos os íons, desde os inorgânicos até macromoléculas, como as proteínas. Os suportes mais empregados são o papel de filtro, acetato de 
celulose, gel de amido, gel de ágar ou gel de acrílico.

A Eletroforese sem suporte é um método baseado num limite móvel vertical entre uma solução tamponada de proteína e uma solução sobrenadante menos densa formada pelo tampão sozinho. Um gradiente elétrico de poucos volts por centímetro, aplicado através do limite, causa a migração da proteína na direção determinada por sua carga a um dado pH e o limite se move de acordo. Observa-se a posição do limite pela brusca mudança do índice de refração. Emprega-se um sistema óptico complexo baseado em fotografia schlieren a fim de dar resultados que se podem interpretar tanto qualitativa quanto quantitativamente. Assim, em geral, uma mistura de proteínas mostrará, após eletroforese, uma série de picos gaussianos mais ou menos separados, de acordo com a mobilidade relativa das várias espécies.

A Eletroforese com suporte também pode ocorrer nos poros de uma folha de papel de filtro ou no meio de um gel. Coloca-se sobre uma placa de vidro uma tira de papel de filtro com as extremidades mergulhadas em soluções tamponadas. Um par de eletrodos ligados aos terminais de uma fonte de voltagem de c.c. ajustável fazem o contato elétrico entre as duas soluções. Umedece-se a folha com um eletrólito diluído, coloca-se a amostra no centro com um conta-gotas e aplica-se um potencial de várias centenas de volts. Deve-se cobrir a faixa de papel de algum modo para evitar a evaporação do solvente e, a não ser nas unidades menores, deve-se esfriá-la com água, pois se dissipa no papel considerável potência elétrica. Podem-se combinar essas duas funções em uma tampa colocada em contato com o papel e munida de serpentinas de refrigeração. A separação das espécies carregadas dependerá primariamente de suas mobilidades relativas. Em alguns casos, pode haver interação específica entre o soluto e o papel, que tenderá a retardar a passagem ao longo do papel, como na cromatografia. Observar que qualquer efeito cromatográfico está agindo paralelamente ao campo elétrico. Um procedimento comparável é a eletroforese em gel. Pode-se moldar diretamente uma camada delgada de um gel no leito de um aparelho com papel de filtro pendendo pelas extremidades, agindo como pavio a fim de estabelecer contato com os recipientes dos eletrodos. Mostraram-se úteis os seguintes géis: gel de amido, ágar, agarose, copolímeros de cloreto e acetato de polivinila, poliacrilamida e acetato de celulose. Também se utilizou vidro poroso como um suporte para eletroforese. Deve-se sempre proteger a eletroforese efetuada em um meio poroso contra um efeito destrutivo que é a eletrosmose. Está se origina da carga adquirida na superfície do sólido (potencial zeta). A carga faz com que a substância aja quase como um fraco trocadorde íons atraindo íons de carga oposta. Portanto haverá um verdadeiro movimento de íons (principalmente componentes do tampão) em direção ao eletrodo de sinal oposto ao da carregado sólido. Isso produzirá um fluxo real do solvente na mesma direção, por osmose, tendendo a manter constante a concentração do tampão. Suportes diferentes variam tanto em sinal como em valor dos potenciais zeta. Algumas vezes é possível misturarem-se duas substâncias na preparação de um gel, de modo que o efeito eletrosmótico de uma será compensada pela outra. Quando não se puder fazer isso (como com papel ou vidro poroso), o efeito deverá ser medido e corrigido. Geralmente, a medida é feito adicionando-se uma espécie não-carregada à amostra e observando quão distante ela se move durante a experiência. Na Eletrocromatografia, a aplicação concomitante das técnicas de eletroforese e cromatografia em um suporte de papel mostrou-se muito proveitosa. A folha de papel, comumente, é 
suspensa verticalmente no solvente (geralmente um tampão) descendo de um reservatório no topo. Aplicase o campo elétrico horizontalmente através de algum tipo de tiras de contato ao longo dos lados da cortina de papel.

\section{REFERÊNCIAS}

ALMEIDA, J. R.; SILVA, C. E.; SILVA, C. V. V.; AGUIAR, L. A.; GARCIA, V. S.; SOUZA, C. P.; LENZ, E. R. S.; LINS, G. A.; ALMEIDA, S. M.. Multifatorialidade em saúde ambiental. Environmental Scientiae, v.1, p.26-47, 2019. DOI: https://doi.org/10.6008/CBPC2674-6492.2019.002.0002
ALMEIDA, J. R.; SILVA, C. E.; SILVA, C. V. V.; AGUIAR, L. A.; GARCIA, V. S.; SOUZA, C. P.; LENZ, E. R. S.; LINS, G. A.; ALMEIDA, S. M.. Política e economia de vigilância em saúde ambiental. Environmental Scientiae, v.1, p.1-25, 2019. DOI: https://doi.org/10.6008/CBPC2674-6492.2019.002.0001

A CBPC - Companhia Brasileira de Produção Científica (CNPJ: 11.221.422/0001-03) detém os direitos materiais desta publicação. Os direitos referem-se à publicação do trabalho em qualquer parte do mundo, incluindo os direitos às renovações, expansões e disseminações da contribuição, bem como outros direitos subsidiários. Todos os trabalhos publicados eletronicamente poderão posteriormente ser publicados em coletâneas impressas sob coordenação da Sapientiae Publishing, da Companhia Brasileira de Produção Científica e seus parceiros autorizados. Os (as) autores (as) preservam os direitos autorais, mas não têm permissão para a publicação da contribuição em outro meio, impresso ou digital, em português ou em tradução. 